American Journal of Applied Sciences 9 (3): 399-404, 2012

ISSN 1546-9239

(C) 2012 Science Publications

\title{
Numerical Simulation of Micro-Channel Heat Sink with Dimpled Surfaces
}

\author{
Suabsakul Gururatana \\ Mechanical Engineering Program, Faculty of Engineering at Si Racha \\ Kasetsart University Si Racha Campus, Chonburi, 20230 Thailand
}

\begin{abstract}
Problem statement: The power density of electronic devices has been increasing along with the rapid technology development. Cooling off electronic systems is essential in controlling the component temperature and avoiding any hot spot. The micro-devices are now extensively used in electronic application especially for cooling the computer chip. Approach: Micro-channel heat sinks are adopted in electronics cooling together with different technologies to enhance the heat transfer process. To improve the cooling process in heat sink, dimples are used because they are simple and cheap technologies. Therefore, this study aims to investigate the micro-channel heat sink with dimples. Results: The heat transfer enhancement in micro-channel heat sink using dimples is useful when the Reynolds number is greater than 125 . Conclusion: The results of this study can help designing microchannel heat sinks for electronics cooling by employing the concept of dimples.
\end{abstract}

Key words: Heat transfer enhancement, cooling process, micro-channel, heat sink, dimples

\section{INTRODUCTION}

The rapid development of engineering application for micro-devices, micro-manufacturing, micro-systems is creating demand for better understanding the micro scale phenomena. Nowadays, the micro-devices are widely used in electronic application especially for cooling the computer chip. Early work on the microchannel heat sink, it was examined by Tuckerman and Pease (1981). They showed a feasibility study to use force convection micro-channel in electronic cooling. This heat sink had every low thermal resistance. The study also showed that the microchannel presented good heat dissipation rate from the electronic chips and this results guaranteed the potential of this technology. Samalam (1989) analytically and numerically studied heat transfer on micro-channel heat sink for cooling silicon electronic chip. They presented the exact equations in order to calculate heat transfer and showed the optimum dimensions for width and channel spacing. After using the optimum values, micro-channel heat sink had lower thermal resistance than original model. Wang and Peng (1994) experimentally investigated the convection of water and methanol through micro-channels with rectangular cross-sections. They found that the liquid convection characteristics were quite different from those of the conventional cases. The fully developed turbulent heat transfer was predicted by the Dittus-Boelter correlations which were modifying the empirical constant coefficients. The characteristics of convective heat transfer were strongly affected by liquid temperature, velocity and micro-channel size. Peng and Peterson (1996) experimentally and analytically studied the heat transfer and flow field characteristic for water flow in micro-channel. Their results indicated that the Reynolds number for transition from laminar to turbulent flow become much smaller than that for flow in the regular channels. The aspect ratio of the channel cross-section had the significant effect on the convective heat transfer. Empirical correlations were suggested for prediction of the heat transfer for both laminar and turbulent regimes. Vafai and Zhu (1999) proposed the new concept of micro-channel heat sink, two layers with counter flow. They numerically investigated micro-channel heat sink using finite element method and optimized the geometric parameters as well. The result showed that two-layer model was not significantly more complicated than the one layer model. In addition, pressure drop for the two-layer heat sink was found to be considerably smaller than that of the one layer heat sink. Lee and Vafai (1999) presented the comparative study between two advance technologies, jet impingement and micro-channel cooling. They found that if target plate is large, jet impingement is better than micro-channel. When the target plate is smaller than $0.07 \times 0.07 \mathrm{~m}$, the microchannel cooling is more preferable than jet impingement. Qu and Mudawar (2002) numerically investigated three dimensional heat transfers in the 
silicon micro-channel heat sink using the finite difference method. They concluded that the increasing Reynolds number increased the length of the developing region. Fully developed flow might not be achieved inside the heat sink for high Reynolds numbers. The results clearly showed heat transfer performance is improved and the pressure drop becomes higher.

The heat transfer and flow characteristic for channel with dimples and protrusions on wall at Reynolds number of 380 to 30,000 was experimentally investigated by Ligrani et al. (2001). The results showed that when dimples and protrusions were used in channel, the heat transfer was enhanced. However, local friction factor was higher. To explain that dimples cause friction reduction, Lienhart et al. (2008) experimentally and numerically studied turbulent flow over dimples both internal and external flow. This study claimed that heat transfer augmentation using shallow dimples can be achieved without significant additional pressure drop. The cooling augmentation in internal turbine blade was numerically conducted by Xie and Sunden (2010). The array of dimples are performed in the blade and the study focused flow field in high range of Reynolds number $(100,000-600,000)$. The study claimed that the dimple is an appropriate method to enhance cooling in the turbine blade with very low pressure loss penalty. Hwang et al. (2010) numerically studied dimples and protrusions surfaces for compact heat exchangers. They claim that heat transfer was enhanced with Reynolds number. Likewise, the friction factor was increased with Reynolds number as well. The thermal enhancement performance was justified by performance factor. It was observed that when Reynolds number is increased, the performance factors for all cases were rapidly decreased.

The comericial computational fluid dynamics software (Fluent) was adopted by Salih et al. (2009) to study effect of buoyancy force for two dimensional flows. The results showed that the CFD software can predicted the reliable results of momentum and energy. Also, the 2D flow over half circular shape was studied by Pochai (2010). The Finite element technique was used to predict the flow field. The prediction presented that the reasonable flow pattern can be observed and the circulation zone behind the half circular shape can also be seen.

According to the literature review, it can be found that the micro-channel heat sink is the effective for small electronics device. To increase heat transfer, the extended surfaces, fin or pin-fin, cannot be achieved because the limit of available space. The dimpled surface is alternative and simple way to enhance heat transfer in micro-channel heat sink. This study aims to perform parametric study and numerically investigate the heat transfer performance of dimpled surface in micro-channel heat sink.

Governing equations and numerical method: To focus on the fundamentals of flow and heat transfer of micro-channel heat sinks, the two dimensional model is considered. Since the length scale of the channel is small and the Reynolds number is low (as calculated later on), the flow is assumed to be laminar. The properties can be considered as constant because of the narrow temperature range. The continuity, momentum and energy equations for laminar flow can be listed as Eq. 1-4:

$\rho\left(\frac{\partial u}{\partial x}+\frac{\partial v}{\partial y}\right)=0$

$\rho\left(u \frac{\partial u}{\partial x}+v \frac{\partial u}{\partial y}\right)=-\frac{\partial P}{\partial x}+\mu\left(\frac{\partial^{2} u}{\partial x^{2}}+\frac{\partial^{2} v}{\partial y^{2}}\right)$

$\rho\left(u \frac{\partial v}{\partial x}+v \frac{\partial v}{\partial y}\right)=-\frac{\partial P}{\partial y}+\mu\left(\frac{\partial^{2} u}{\partial x^{2}}+\frac{\partial^{2} v}{\partial y^{2}}\right)$

$\rho C_{p}\left(u \frac{\partial T}{\partial x}+v \frac{\partial T}{\partial y}\right)=k\left(\frac{\partial^{2} T}{\partial x^{2}}+\frac{\partial^{2} T}{\partial y^{2}}\right)$

where, $\mathrm{u}$ and $\mathrm{v}$ are the velocity in streamwise and spanwise direction. $\mathrm{P}$ and $\mathrm{T}$ are the pressure and temperature. The $\rho, C_{p}, k$ and $\mu$ which are the fluid properties are density, specific heat, thermal conductivity and dynamics viscosity, respectively. The commercial software package, Fluent version 6.3.26, is used in this study. The governing equations are discretized by the finite volume method and the second order upwind scheme is adopted for spatial discretization of the convection terms. The segregated solver is used in the simulation and the SIMPLE algorithm is employed to couple the pressure and velocity (Patankar, 1980). The convergence criteria of iterative solution have been insured when the residual of all variables are less than specific values. The specified value is $10^{-5}$ for continuity, momentum and energy equations.

Geometry and boundary condition: For 2D baseline case, the half circular shape dimple is selected to study and the typical computational domain is illustrated in Fig. 1. The rectangular shape is considered as a microchannel with length of $0.004 \mathrm{~m}$ and width of $0.001 \mathrm{~m}$. 
Am. J. Applied Sci., 9 (3): 399-404, 2012



Fig. 1: Computational domain for 2D micro-channel heat sink with dimples

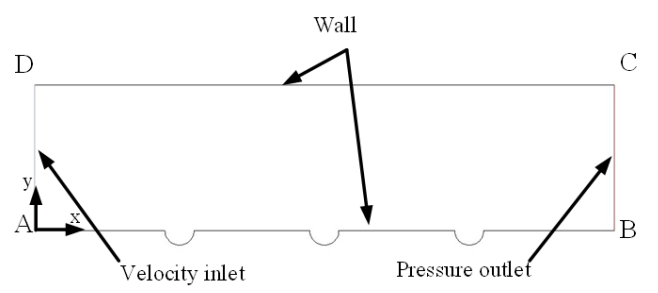

Fig. 2: Boundary conditions for 2D micro-channel heat sink with dimples

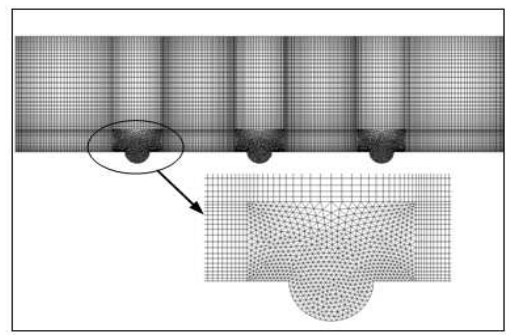

Fig. 3: Structured and unstructured mesh for 2D-micro channel with dimples

Three half circular shape dimples are located at the bottom of channel. The boundary conditions for microchannel heat sink are shown in Fig. 2. The upper, lower and dimples are defined as wall with non-slip condition. The velocity inlet and pressure outlet conditions are used on region $\mathrm{AD}$ and $\mathrm{BC}$, respectively. Uniform velocity of $3 \mathrm{~m} \mathrm{sec}^{-1}$ is employed for the flow inlet in the $\mathrm{x}$ direction. For heat transfer boundary condition, the constant temperature of $350 \mathrm{~K}$ is defined on lower and dimples surface and the upstream bulk temperature of inlet flow is set to $300 \mathrm{~K}$. The adiabatic condition is defined at upper wall. In practical, flows in electronics cooling devices are generally laminar so that the Reynolds number based on the channel width is calculated as 207 .
Table 1: Parameters Of 2D micro-channel heat sink with dimples

Parameters

\begin{tabular}{lr}
\hline Channel width $\left(\mathrm{w}_{\mathrm{c}}\right)(\mathrm{m})$ & 0.00100 \\
Channel length $\left(\mathrm{l}_{\mathrm{c}}\right)(\mathrm{m})$ & 0.00400 \\
Dimple length $\left(\mathrm{r}_{1}\right)(\mathrm{m})$ & 0.00005 \\
Dimple depth $\left(\mathrm{r}_{2}\right)(\mathrm{m})$ & 0.00005 \\
Temperature on the fin surface, $\mathrm{T}_{\mathrm{w}}(\mathrm{K})$ & 350.00000 \\
Inlet average bulk temperature, $\mathrm{T}_{\mathrm{a}}(\mathrm{K})$ & 300.00000 \\
Inlet average air velocity, $\mathrm{U}_{\mathrm{a}}(\mathrm{m} / \mathrm{s})$ & 3.00000 \\
\hline
\end{tabular}

Table 2: Overall performances with different grid systems for 2D micro-channel heat sink with dimples

\begin{tabular}{lcc}
\hline Cases & Coarse grid & Fine grid \\
\hline Number of elements & 8,138 & 16,364 \\
Heat transfer rate $(w)$ & 33.65 & 33.46 \\
Pressuredrop $(\mathrm{Pa})$ & 8.16 & 8.34 \\
\hline
\end{tabular}

The working fluid, air, is considered as an ideal-gas. Finally, the main parameters of 2D baseline case are shown in Table 1.

Grid independence study: The 2D baseline microchannel heat sink with dimples is meshed using structure and un-structured and it is presented in Fig. 3. The baseline case contains a total number of elements of 16,364. The grid independence is studied for all cases and one of the examples which is microchannel heat sink with uniform velocity of $5 \mathrm{~m} \mathrm{sec}^{-1}$ is shown in Table 2.

It can be seen that when the grid increases from 8,138 to 16,364 , the heat transfer rate and pressuredrop change only 6 and $2 \%$, respectively.

\section{MATERIALS AND METHODS}

The two dimensional micro-channel heat sink with dimple is numerically studied and the commercial Computational Fluid Dynamics (CFD) software, Fluent, is used to determine heat transfer and flow field inside channel. The conventional personal computer with AMD Sempron LE-1640 and RAM 1024MB DDR2 is used to operate CFD software.

\section{RESULTS AND DISCUSSION}

2D Micro-channel with dimples baseline case (Reynolds number of 207): The 2D baseline microchannel heat sink with dimples is studied and the Reynolds number of 207 is chosen for baseline case. The stream function and velocity vector are presented in Fig. 4. The velocity boundary layer smoothly develops along upper and lower surfaces and then it is initially interrupted by first dimple. The trend of the overall flow velocity and magnitude are quite reasonable. 
Am. J. Applied Sci., 9 (3): 399-404, 2012

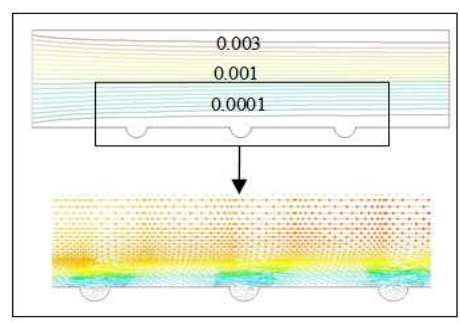

Fig. 4: The stream function and velocity vector for micro-channel heat sink with dimples

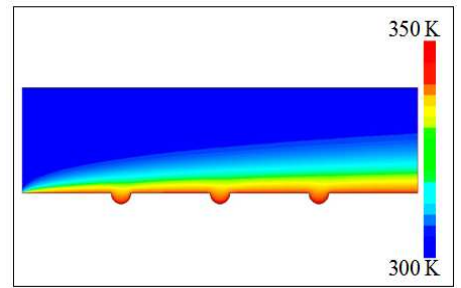

Fig. 5: The temperature distribution for micro-channel heat sink with dimples

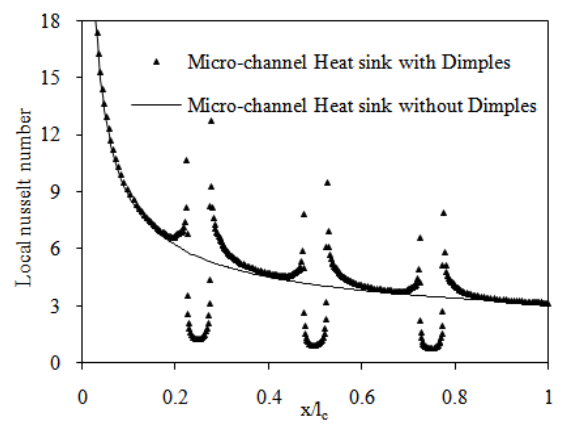

Fig. 6: The local Nusselt number for micro-channel heat sinks

Temperature contour inside channel is illustrated in Fig. 5. The thermal boundary layer develops on the channel surface in front of first dimple and is similar to velocity boundary layer. It can also be seen that thermal boundary layer is disturbed by dimples.

The local heat transfer coefficient $\left(h_{x}\right)$ is defined with the bulk mean temperature and correspondingly, the local Nusselt number $\left(\mathrm{Nu}_{\mathrm{x}}\right)$ can be defined Eq. 5 and 6 :

$\mathrm{q}^{\prime \prime}=\mathrm{h}_{\mathrm{x}}\left(\mathrm{T}_{\text {max }}-\mathrm{T}_{\text {mean }}\right)$

$\mathrm{Nu}_{\mathrm{x}}=\frac{\mathrm{h}_{\mathrm{x}} \mathrm{W}_{\mathrm{c}}}{\mathrm{k}}$

Where:

$\mathrm{k}$

$=$ The thermal conductivity

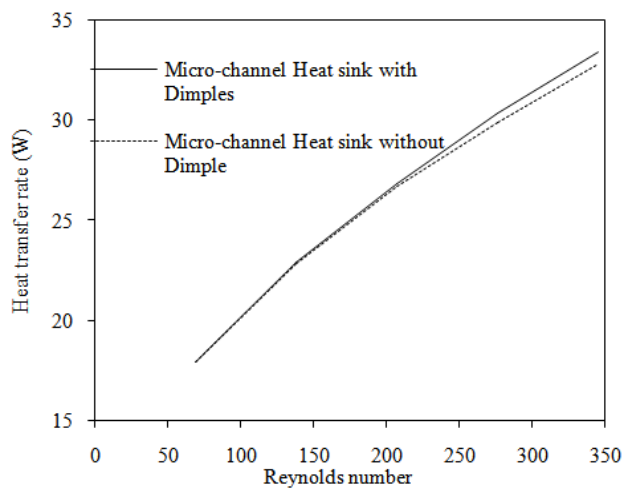

Fig. 7: The effect of Reynolds number on heat transfer rate for micro-channel heat sinks

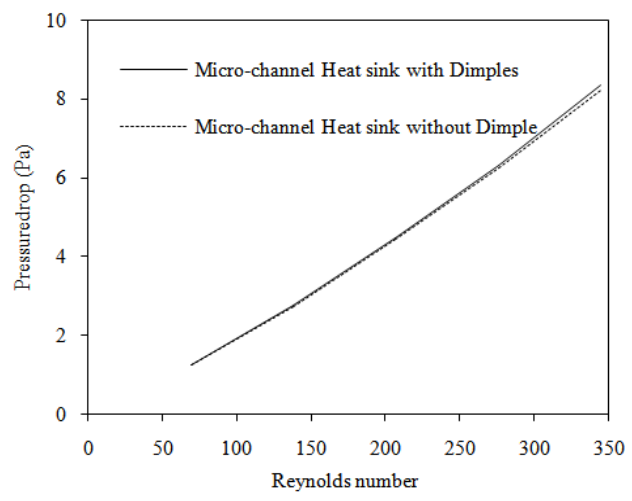

Fig. 8: The effect of Reynolds number on pressuredrop for micro-channel heat sinks

q" $\quad=$ Heat flux

$\mathrm{T}_{\max }$ and $\mathrm{T}_{\text {mean }}=$ The maximum and mean temperatures, respectively

The local Nusselt number of micro-channel heat sink with and without dimples along lower wall and dimple is shown in Fig. 6. It can be seen that the local Nusselt number at upstream for heat sink with and without dimples are similar. When the flow reaches each dimple, heat transfer quickly increases. However, inside dimple heat transfer of heat sink with dimples is worse than heat sink without dimples. At the rear end of each dimple, heat transfer is clearly enhanced as well because the flow circulation near rear end provides well convection heat transfer.

Effect of Reynolds numbers on micro-channel with dimples: The overall heat transfer rate and pressure drop of heat sink with and without dimples are shown in Fig. 7 and 8, respectively. It is reasonable to see that 
heat transfer and pressuredrop increase with Reynolds number. Due to the laminar flow feature, the relationship between pressure drop and Reynolds number is almost linear. When Reynolds number increases from 100-300, pressuredrop rises more than $300 \%$; however, heat transfer enhances only $30 \%$.

To compare the heat transfer and pressuredrop augmentation, the Heat Transfer Enhancement Performance (HTEP) is used and it can be expressed as Eq. 7:

$$
\mathrm{HTPE}=\frac{\left(\mathrm{Q}_{\mathrm{d}} / \mathrm{Q}_{\mathrm{c}}\right)}{\left(\Delta \mathrm{P}_{\mathrm{d}} / \Delta \mathrm{P}_{\mathrm{c}}\right)^{1 / 3}}
$$

where, $\mathrm{Q}_{\mathrm{d}}$ and $\mathrm{Q}_{\mathrm{c}}$ are heat transfer rate of heat sink with and without dimples. The $\Delta \mathrm{P}_{\mathrm{d}}$ and $\Delta \mathrm{P}_{\mathrm{c}}$ are pressuredrop of heat sink with and without dimples. The Fig. 9 presents heat transfer enhancement performance for heat sink with dimples. Likewise, the enhancement performance increases with Reynolds number. At Reynolds number $<125$, the performance is less than 1. Therefore, the heat transfer enhancement in microchannel heat sink using dimples is useful when the Reynolds number is greater than 125 .

Validation of numerical results: The commercial software package has been validated at least for problems as simple as in this study. Further validation is performed in this study for the numerical procedures and settings. Since there is no test data found in literature, a simplified model for a laminar flow and heat transfer inside 2D channel is considered. This simplified model is simulated at Reynolds number of 1,000 based on the hydraulic diameter. The wall and inlet air temperature are 320 and $300 \mathrm{~K}$, respectively.

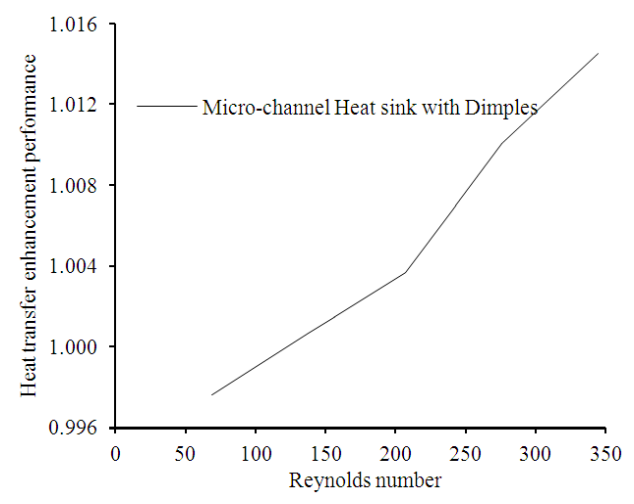

Fig. 9: The effect of Reynolds number on heat transfer enhancement performance for micro-channel heat sinks
The theoretical Nusselt number is 7.54 (Bergman et al., 2011). The Nusselt number from numerical result is 7.48 at Reynolds number of 1,000. It can be seen that the numerical result is different from theoretical by only $2.7 \%$. Thus, it is concluded that numerical results in this study are consistent with the literature and experimental values.

\section{CONCLUSION}

The fluid flow and heat transfer of micro-channel heat sinks with dimples have been investigated by using numerical simulation. The effects of Reynolds number are explored. The conclusions can be drawn from the present study as follows:

- Dimple clearly improves micro-channel heat sink performance in enhancing local Nusselt number especially at the front and rear end of dimple

- Heat transfer increases with the Reynolds number and at the same time, the pressuredrop increases as well

- The heat transfer enhancement in micro-channel heat sink using dimples is useful when the Reynolds number is greater than 125

\section{ACKNOWLEDGMENT}

This study is achieved with the supports from the Faculty of Engineering at $\mathrm{Si}$ Racha, Kasetsart University $\mathrm{Si}$ Racha campus and Mechanical Engineering Department, Kasetsart University. Author appreciates Associate Professor Dr. Xianchang Li from Lamar University, Beaumont, TX, USA for his support and advice.

\section{REFERENCES}

Bergman, T.L., F.P. Incropera, D.P. DeWitt and A.S. Lavine, 2011. Introduction to Heat Transfer. 6th Edn., John Wiley and Sons, Hoboken, ISBN: 0470501960, pp: 960.

Hwang, S.D., H.G. Kwon and H.H. Cho, 2010. Local heat transfer and thermal performance on periodically dimple-protrusion patterned walls for compact heat exchangers. Energy, 35: 5357-5364. DOI: 10.1016/j.energy.2010.07.022

Lee, D.Y. and K. Vafai, 1999. Comparative analysis of jet impingement and microchannel cooling for high heat flux applications. Int. J. Heat Mass Transfer, 42: $\quad 1555-1568 . \quad$ DOI: $10.1016 /$ S00179310(98)00265-8 
Lienhart, H., M. Breuer and C. Koksoy, 2008. Drag reduction by dimples? - A complementary experimental/numerical investigation. Int. J. Heat Fluid Flow, 29: 783-791. DOI: 10.1016/j.ijheatfluidflow.2008.02.001

Ligrani, P.M., G.I. Mahmood, J.L. Harrison, C.M. Clayton and D.L. Nelson, 2001. Flow structure and local Nusselt number variations in a channel with dimples and protrusions on opposite walls. Int. J. Heat Mass Transfer, 44: 4413-4425. DOI: 10.1016/S0017-9310(01)00101-6

Patankar, S.V., 1980. Numerical Heat Transfer and Fluid Flow. 1st Edn., Hemisphere Publication Corporation, Washington, ISBN: 0070487405, pp: 197.

Peng, X.F. and G.P. Peterson, 1996. Convective heat transfer and flow friction for water flow in microchannel structures. Int. J. Heat Mass Transfer, 39: 2599-2608. DOI: 10.1016/00179310(95)00327-4

Pochai, N., 2010. A numerical treatment of air flow model in the area under the station platform of Thailand BTS sky train. Am. J. Applied Sci., 7: 1500-1503. DOI: 10.3844/ajassp.2010.1500.1503

Qu, W. and I. Mudawar, 2002. Analysis of threedimensional heat transfer in micro-channel heat sinks. Int. J. Heat Mass Transfer, 45: 3973-3985. DOI: 10.1016/S0017-9310(02)00101-1
Salih, E.A., T.S.Y. Choong, S.Y. Sergie, N.L. Chin and O.M. Ibrahim, 2009. The effect of buoyancy force in computational fluid dynamics simulation of a two-dimensional continuous ohmic heating process. Am. J. Applied Sci., 6: 1902-1908 DOI: 10.3844/ajassp.2009.1902.1908

Samalam, V.K., 1989. Convective heat transfer in microchannels. J. Elec. Mater., 18: 611-617. DOI: 10.1007/BF02657475

Tuckerman, D.B. and R.F.W. Pease, 1981. Highperformance heat sinking for VLSI. IEEE Elect. Device Lett., 2: 126-129. DOI: 10.1109/EDL.1981.25367

Vafai, K. and L. Zhu, 1999. Analysis of two-layered micro-channel heat sink concept in electronic cooling. Int. J. Heat Mass Transfer, 42: 2287-2297. DOI: 10.1016/S0017-9310(98)00017-9

Wang, B.X. and X.F. Peng, 1994. Experimental investigation on liquid forced-convection heat transfer through microchannels. Int. J. Heat Mass Transfer, 37: 73-82. DOI: 10.1016/00179310(94)90011-6

Xie, G. and B. Sunden, 2010. Numerical predictions of augmented heat transfer of an internal blade tipwall by hemispherical dimples. Int. J. Heat Mass Transfer, 53: 5639-5650. DOI: 10.1016/j.ijheatmasstransfer.2010.08.019 